\title{
Actividad antifúngica y perfil de seguridad del producto natural derivado del aceite de maravilla ozonizado $\left(\mathrm{AMO}_{3}\right)$ en dermatofitos*
}

\author{
Pamela Thomson M., Sonia Anticevic C., Héctor Rodríguez B. y Víctor Silva V.
}

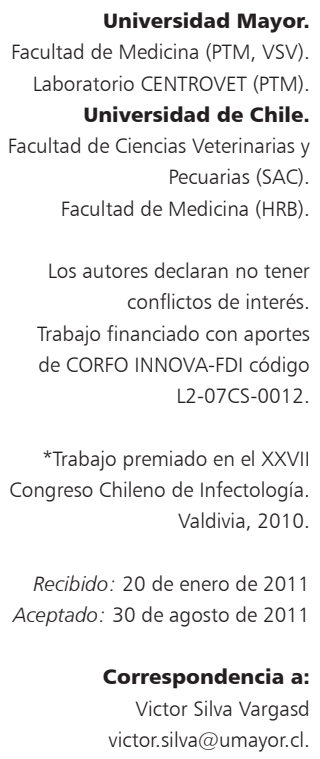

Universidad Mayor. Facultad de Medicina (PTM, VSV) Laboratorio CENTROVET (PTM). Universidad de Chile. Facultad de Ciencias Veterinarias y Pecuarias (SAC) Facultad de Medicina (HRB)

Los autores declaran no tener conflictos de interés. Trabajo financiado con aportes de CORFO INNOVA-FDI código L2-07CS-0012

*Trabajo premiado en el XXVII Congreso Chileno de Infectología. Valdivia, 2010

Recibido: 20 de enero de 2011 Aceptado: 30 de agosto de 2011

Correspondencia a: Victor Silva Vargasd victor.silva@umayor.cl.

\section{In vitro antifungal susceptibility, in vivo antifungal activity and security from a natural product obtained from sunrise oil $\left(\mathrm{AMO}_{3}\right)$ against dermatophytes}

This work studied safety and antifungal activity of ozonized sunflower oil $\left(\mathrm{AMO}_{3}\right)$ against dermatophytes. $\mathrm{AMO}_{3}$ was prepared through a new original process that modifies the oil before ozonation by alcoholic catalytic esterification. Susceptibility was studied in 41 dermatophytes by agar diffusion and broth microdilution tests. The experimental model to assess the topical safety of the oil included $60 \mathrm{CF} 1$ mice divided in three groups that were treated with vaseline (control), $1 \% \mathrm{AMO}_{3}$ and 50\% $\mathrm{AMO} 3$ (overdose), respectively. Then, experimental dermatophytosis was induced in CF1 mice. Seventy-five individuals were selected and divided in 5 groups that were treated once a day with placebo, cream with $1 \%, 2 \%$ and $3 \% \mathrm{AMO}_{3}$ plus an untreated control group. This new natural product showed antifungal activity against all strains studied. The MIC ranged between was 0,125 and $1 \%$, while minimum fungicidal concentration (MFC) was $2 \%$. The application of vaseline and $\mathrm{AMO}_{3} 1 \%$ and $50 \%$ did not produce clinical or histopathological lesions. The mice with dermatophytosis that were treated with $1 \%, 2 \%$ and $3 \% \mathrm{AMO}_{3}$ showed $100 \%$ clinical cure and $94 \%$ average mycological cure, exceeding placebo and control groups $(\mathrm{p}<0,05)$. This product exhibits high antifungal activity and could be a safe alternative for ringworm topical treatment.

Key words: Natural antifungal, ozonized oil, dermatophytosis.

Palabras clave: Antifúngico natural, aceite ozonizado, dermatofitosis.

\section{Introducción}

L as dermatofitosis continúan siendo una causa importante de consulta, tanto en humanos como en animales ${ }^{1}$. Son afecciones cutáneas causadas por hongos del grupo dermatofitos, con afinidad para crecer sobre la queratina, la que digieren enzimáticamente y consumen como principal fuente de energía. Los dermatofitos están integrados por los géneros Microsporum, Trichophyton y Epidermophyton, capaces de invadir y mantenerse en tejidos queratinizados, como el estrato córneo de la piel, pelos y uñas, pudiendo transmitirse entre personas, de animales al hombre y viceversa ${ }^{2}$. Clínicamente se caracterizan por producir lesiones circulares con un grado variable de eritema, descamación, prurito y alopecia cuando afecta una zona pilosa $\mathrm{s}^{2-4}$.

Según su hábitat y preferencias de hospederos, los dermatofitos se clasifican en tres grupos: geofílicos o habitantes del suelo, que ocasionalmente son patógenos para el hombre y los animales; zoofílicos, cuyo hospedero natural son los animales, pero frecuentemente afectan al hombre; y antropofílicos, patógenos exclusivamente humanos ${ }^{1-4}$. El diagnóstico de las dermatofitosis se inicia en la anamnesis, con una completa y detallada historia clínica. Se estima que éste es el procedimiento más importante en dermatología. Sin embargo, el diagnóstico clínico de dermatofitosis es de sospecha, comprobándose la infección a través del estudio micológico destinado a observar el agente en parasitismo y aislándolo in vitro para su posterior identificación ${ }^{2,4}$.

La decisión de tratar este tipo de infecciones fúngicas con un preparado tópico o sistémico debe individualizarse para cada paciente, según el tipo y extensión de la lesión. La vía de administración más frecuente es la tópica, la que, con excepción de tinea capitis y tinea unguium, está indicada en lesiones muy circunscritas, en mujeres embarazadas o durante la lactancia, para evitar recidivas post-tratamiento y en algunos casos asociado a terapias antifúngicas orales ${ }^{2,5}$. En general, se requiere de una a dos aplicaciones diarias por un período de dos a cuatro semanas, excepto si la lesión está en los espacios interdigitales, en cuyo caso el tiempo se extiende hasta seis semanas. Entre los antifúngicos tradicionales de uso tópico destacan los derivados imidazólicos, como ketoconazol y miconazol; derivados de la piridona, como la ciclopiroxolamina y alilaminas como terbinafina y buterbinafina, comunicándose buena tolerancia y cura clínica-micológica en cerca de $80 \%$ de las dermatofitosis ${ }^{5-7}$. 
El rol creciente de los hongos en las infecciones humanas, unido al aumento clínico y microbiológico de resistencia a los antimicóticos, ha estimulado el desarrollo de nuevos y diversos compuestos con mayor espectro de acción antifúngica y menor toxicidad que las actuales moléculas, encontrando muy buena acogida los productos de origen natural debido a la extensa fuente de metabolitos secundarios con actividad biológica ${ }^{8-10}$, lo que ha llevado a replantear el interés de la industria farmacéutica en el estudio de moléculas a partir de productos naturales previamente conocidos ${ }^{11}$.

Extractos alcohólicos, aceites esenciales y compuestos de naturaleza sulfhídrica aislados de los bulbos de ajos (Allium sativum), así como los aceites derivados de Eucalyptus globosus y otros extractos alcohólicos de plantas silvestres, imidas cíclicas y leguminosas, tienen un efecto antimicótico contra algunos géneros de levaduras, dermatofitos $\mathrm{u}$ otros hongos filamentosos ${ }^{12-18}$. Otro compuesto con actividad antimicrobiana es el aceite de maravilla o girasol ozonizado, siendo el ozono la unidad alotrópica del oxígeno, constituido por moléculas triatómicas de este elemento, que sería el responsable de potenciar la actividad antimicrobiana debido a su poder oxidante, mediante acción directa por radicales libres ${ }^{19,20}$. Según Lezcano $y$ cols., (1996 y 1998), el aceite de maravilla ozonizado tiene actividad fungicida directa en dermatofitos ${ }^{21,22}$.

La actividad antifúngica in vitro del aceite de maravilla ozonizado contra levaduras es superior al aceite de oliva ozonizado. Esta actividad puede ser explicada por la mayor cantidad de ácido oleico en el aceite de maravilla, en relación al linoleico que predomina en el de oliva ${ }^{23}$. Se ha evaluado la actividad antimicrobiana de ambos aceites ozonizados frente a distintas cepas bacterianas, determinándose una actividad similar, excepto en cepas de Pseudomonas aeruginosa, donde el aceite de oliva muestra mayor actividad ${ }^{24}$.

En la actualidad, se plantea la necesidad de conocer nuevas formas de generar potencial antimicrobiano a partir de productos naturales, para mejorar el rendimiento de concentraciones inhibitorias mínimas (CIM) y/o fungicidas mínimas (CFM), así como para realizar un seguimiento protocolizado de seguridad y actividad bajo un modelo experimental en animales. Por lo tanto, el objetivo de la presente investigación fue determinar la actividad antifúngica in vitro e in vivo de un aceite de maravilla obtenido a través de un proceso original que implica la modificación del aceite mediante esterificación catalítica con alcoholes de bajo peso molecular, antes de su ozonificación, denominado $\mathrm{AMO}_{3}$, frente a dermatofitos, por un método cualitativo de difusión en agar y cuantitativo por microdilución en caldo. A su vez, se evaluó la seguridad y respuesta al tratamiento de este producto natural en modelo experimental en ratones $\mathrm{CF} 1$.

\section{Material y Métodos}

\section{Aceite de maravilla ozonizado $\left(\mathrm{AMO}_{3}\right)$}

El aceite de maravilla es tratado previo a su ozonización con alcoholes de bajo peso molecular, tipo alcoholes etílico, metílico o propílico, para ejercer una esterificación catalítica. La calidad de la ozonización es medida a través de índices de peróxido, los cuales deben ser $\geq 400 \mathrm{mEq}$ de $\mathrm{O}_{2}$ activo/ $\mathrm{kg}$ de aceite; índice de yodo el cual debe ser $>100$ gr de yodo por 100 gr de aceite; índice de acidez que debe ser sobre $4 \mathrm{mg}$ de $\mathrm{KOH}$ por gramo de aceite.

\section{Material biológico}

Se incluyeron 41 cepas de dermatofitos: Microsporum canis (n: 15), M. gypseum (n: 10), Trichophyton mentagrophytes (n: 9), T. rubrum (n: 6) у M. nanum (n: 1), aislados de dermatofitosis humanas (n: 19) y animales (n: 22) identificadas por el método estándar ${ }^{4,25}$.

\section{Sensibilidad por método cualitativo de difusión en agar}

Cada cepa se cultivó en agar papa dextrosa (APD) durante 10 días a $25^{\circ} \mathrm{C}$ para estimular la conidiogénesis. Luego se agregó $5 \mathrm{~mL}$ de solución salina $(\mathrm{NaCl}$ 9\%o) estéril para obtener conidios. Con espectrofotómetro se ajustó la concentración a $1 \times 10^{6} \mathrm{ufc} / \mathrm{ml}(\lambda 540 \mathrm{~nm}$ con absorbancia de 0,13 a 0,14 D.O.) y fue sembrado en placa de Petri con agar Sabouraud glucosa (ASG). $\mathrm{AMO}_{3}$ se diluyó en dimetilsulfóxido (DMSO) hasta alcanzar concentraciones seriadas de 16 a 0,03\%. Luego se transfirió $10 \mu 1$ de cada dilución a discos de papel filtro (6 $\mathrm{mm}$ de diámetro). Se utilizó como control un disco con $10 \mu \mathrm{l}$ con DMSO y otro con aceite de maravilla sin ozonizar ${ }^{26}$. Las placas fueron incubadas a $25^{\circ} \mathrm{C}$ durante 10 a 14 días, realizándose ensayos por triplicado. La lectura se efectuó midiendo el diámetro de la zona de inhibición total del crecimiento $^{14,26}$.

\section{Sensibilidad por método cuantitativo de microdilución en caldo}

Para determinar la susceptibilidad antifúngica por microdilución en caldo se adaptó el método indicado por el Clinical Laboratory Standards Institute (CLSI) de Estados Unidos en el documento M38-A ${ }^{27}$. En microplacas de 96 pocillos con fondo redondo, se adicionó $100 \mu \mathrm{l}$ de las diluciones seriadas de $\mathrm{AMO}_{3}$ diluidas en DMSO, obteniendo en cada fila una serie decreciente de concentraciones que fluctuó entre 16 y 0,03\%. Posteriormente, se agregó 100 $\mu 1$ del inóculo fúngico en caldo RPMI 1640 más $0,3 \mathrm{~g} / 1$ de glutamina y 34,54 g/l de tampón ácido sulfónico-3morfolino propano (MOPS) a $\mathrm{pH} 7,0 \pm 0,1$ para obtener una concentración final de dermatofitos en cada pocillo de 0,5 a $2,5 \times 10^{4} \mathrm{ufc} / \mathrm{ml}$. Las placas se incubaron a $30^{\circ} \mathrm{C}$ durante tres días en cámara húmeda. Luego se verificó 
visualmente el crecimiento en la columna del control positivo y la ausencia de éste en el control negativo. Se determinó la menor concentración del $\mathrm{AMO}_{3}$ que inhibió completamente el crecimiento fúngico.

\section{Controles}

La columna A de la microplaca se utilizó como control negativo (C-) adicionando medio RPMI y $\mathrm{AMO}_{3}$, mientras que la columna L se empleó como control de crecimiento positivo de las cepas $(\mathrm{C}+)$, siendo inoculada con el caldo RPMI, aceite sin ozonizar y las cepas correspondientes en cada fila. Las cepas de Candida parapsilosis ATCC 22019 y C. krusei ATCC 6258 fueron utilizadas como control del método ${ }^{27}$.

La CFM fue definida como la menor concentración de $\mathrm{AMO}_{3}$ que impidió el crecimiento del dermatofito al ser subcultivado en placa de Petri con ASG durante 20 días a $25^{\circ} \mathrm{C}^{28}$.

\section{Seguridad del $\mathrm{AMO}_{3}$ en modelo experimental in vivo}

Se trabajó con 60 ratones de la cepa CF1 (30 hembras y 30 machos) obtenidos del Bioterio Central de la Facultad de Medicina de la Universidad de Chile. Éstos se distribuyeron en tres grupos, los que fueron tratados tópicamente con vaselina líquida $(\mathrm{G} 1), \mathrm{AMO}_{3} 1 \%(\mathrm{G} 2)$ y $\mathrm{AMO}_{3} 50 \%$ (G3), siendo este último grupo considerado el expuesto a sobredosis. A cada animal, según el grupo, se le aplicó $100 \mu 1$ de cada producto en el manto piloso de la zona interescapular y abdomen (área desprovista de pelos), una vez al día por 30 días ${ }^{29}$.

\section{Evaluación clínica}

A cada ratón se le realizó diariamente, con apoyo de lupa, observaciones de la presencia o verificación de la ausencia de reacciones cutáneas adversas, como eritema, descamación, prurito y alopecia, a través de una escala arbitraria semi-cuantitativa diseñada para este estudio. A cada signo se le atribuyó un puntaje ascendente de cero a tres, donde 0 fue ausencia de lesión, 1: lesión leve, 2: moderada y 3: abundante manifestación clínica, lo que permitió valorar el grado de daño. Como sumatoria de las cuatro variables clínicas, la escala permitió calificar entre 0 y 12 puntos a los animales que presentaban la mínima y máxima gravedad, respectivamente.

\section{Evaluación histológica}

Se realizó después de 30 días post-inoculación, seleccionando al azar dos animales de cada grupo (G1, G2 y G3). Se tomó biopsias de la zona inter-escapular y abdomen más una tercera del dorso, usada como control no expuesto al producto. Cada muestra fue fijada en formalina al 4\% y luego incluida en bloques de parafina, procesadas y teñidas con hematoxilina-eosina (H\&E) para su evaluación.

\section{Actividad antifúngica de $\mathrm{AMO}_{3}$ en modelo de dermatosis experimental in vivo}

El modelo experimental de dermatofitosis se realizó en 90 ratones Mus musculus de la cepa CF1 (igual proporción de hembras y machos). A los animales se les aplicó betametasona al 0,05\% vía tópica, en la zona inter-escapular, cada 24 horas y por 7 días para producir inmunosupresión local ${ }^{30}$. Al octavo, los animales fueron sedados con isofluorano al $2 \%$ y oxígeno. Todos los animales fueron depilados, en la zona inter-escapular en un área de $1 \mathrm{~cm}^{2}$ e inoculados con $100 \mu 1$ de la solución 2 Mc Farland de T. mentagrophytes en solución salina con tween 80 al $0,05 \%$, cada 24 horas por 7 días $^{31,32}$. Luego se esperaron 10 días para la aparición de signos clínicos concordantes con una dermatofitosis ${ }^{33}$. Paralelamente se realizó un estudio micológico (directo y cultivo) de los pelos tonsurados para confirmar la dermatofitosis.

Al día 30 se seleccionaron 75 ratones para conformar cinco grupos de 15 individuos, que fueron sometidos a distintos esquemas de tratamiento durante 30 días consecutivos con una aplicación diaria de crema con $\mathrm{AMO}_{3}$ al $1 \%$, con $\mathrm{AMO}_{3}$ al $2 \%$, con $\mathrm{AMO}_{3}$ al $3 \%$, no tratados o control y tratados con crema $\sin \mathrm{AMO}_{3}$ o placebo. Cada signo clínico fue evaluado diariamente y se registró la evolución, siguiendo la escala arbitraria mencionada previamente. Al final de los 30 días, se repitió el cultivo para evaluar cura micológica, tomando la muestra por duplicado desde el manto piloso con gasa estéril de $1 \mathrm{~cm}^{2}$.

\section{Cura clínica y micológica}

La primera se definió como la disminución total o parcial de las lesiones en al menos ocho puntos entre los días 1 y 30 de tratamiento. La segunda se consideró si los cultivos pos-tratamiento fueron negativos.

\section{Comité de bioética}

El estudio de seguridad y actividad antifúngica de $\mathrm{AMO}_{3}$ en ratones fue revisado y aprobado por el Comité de Bioética sobre Investigación en Animales de la Facultad de Medicina de la Universidad de Chile, antes de su ejecución.

\section{Análisis estadístico}

Ensayos in vitro se realizaron en triplicado y se expresaron en la media de valores con sus respectivos rangos registrados. Los datos in vivo se analizaron mediante ANOVA, seguido del test de Bonferroni considerando un $p \leq 0,05$ como criterio de significancia estadística.

\section{Resultados}

La información obtenida indica que el producto natural a base de aceite de maravilla denominado $\mathrm{AMO}_{3}$, tiene actividad antifúngica frente a todas las especies de 
dermatofitos analizadas, observándose un halo de inhibición del crecimiento a partir de la concentración al 1\% por el método de difusión en agar. La mayor inhibición se registró con $\mathrm{AMO}_{3}$ al $16 \%$ en cepas de $M$. nanum y T. rubrum, evidenciando promedios de halos de 38 y $33 \mathrm{~mm}$ de diámetro, respectivamente. Por el contrario, $\mathrm{AMO}_{3}$ al 0,5\% demostró actividad antifúngica sólo contra cepas de $M$. canis y $M$. gypseum (Figura 1). Los discos controles con aceite de maravilla sin ozonizar y DMSO no registraron halo de inhibición.

Los resultados presentados de la Tabla 1 indican que los valores de CIM para $\mathrm{AMO}_{3}$ frente a dermatofitos están en un rango promedio de 0,125 a 1\%; con valores de $\mathrm{CIM}_{90}$ que fluctúan entre 0,25 y 1\%. La CFM fue menor o igual a $2 \%$ para las especies de dermatofitos, lo que indica que $\mathrm{AMO}_{3}$ presenta un efecto fungicida sobre estos hongos a una concentración levemente superior a la $\mathrm{CIM}_{90}$. Las cepas controles de levaduras, presentaron valores de $\mathrm{CIM}_{50}$ y CIM $_{90}$ similares a los dermatofitos. Por el contrario, no se detectó CFM con las concentraciones empleadas en esta investigación.

La evaluación clínica de seguridad en el modelo in vivo durante los 30 días de inoculaciones de vaselina, $\mathrm{AMO}_{3} \mathrm{al}$ $1 \%$ y $\mathrm{AMO}_{3}$ al $50 \%$, demostraron ausencia de reacciones eritematosas, descamativas, pruriginosas y alopécicas, tanto en la zona inter-escapular como en la zona del abdomen desprovista de pelos. La Figura 2, muestra los cortes histológicos más representativos y corresponde a animales de los tres grupos del diseño estudiado. Las preparaciones teñidas con $\mathrm{H} \& \mathrm{E}$, muestran ausencia de hemorragia, inflamación o edema en los estratos de las tres capas cutáneas observadas.

La Figura 3 muestra el seguimiento de la evolución clínica obtenida del registro de datos a través de la escala arbitraria establecida. Los ratones seleccionados presen-

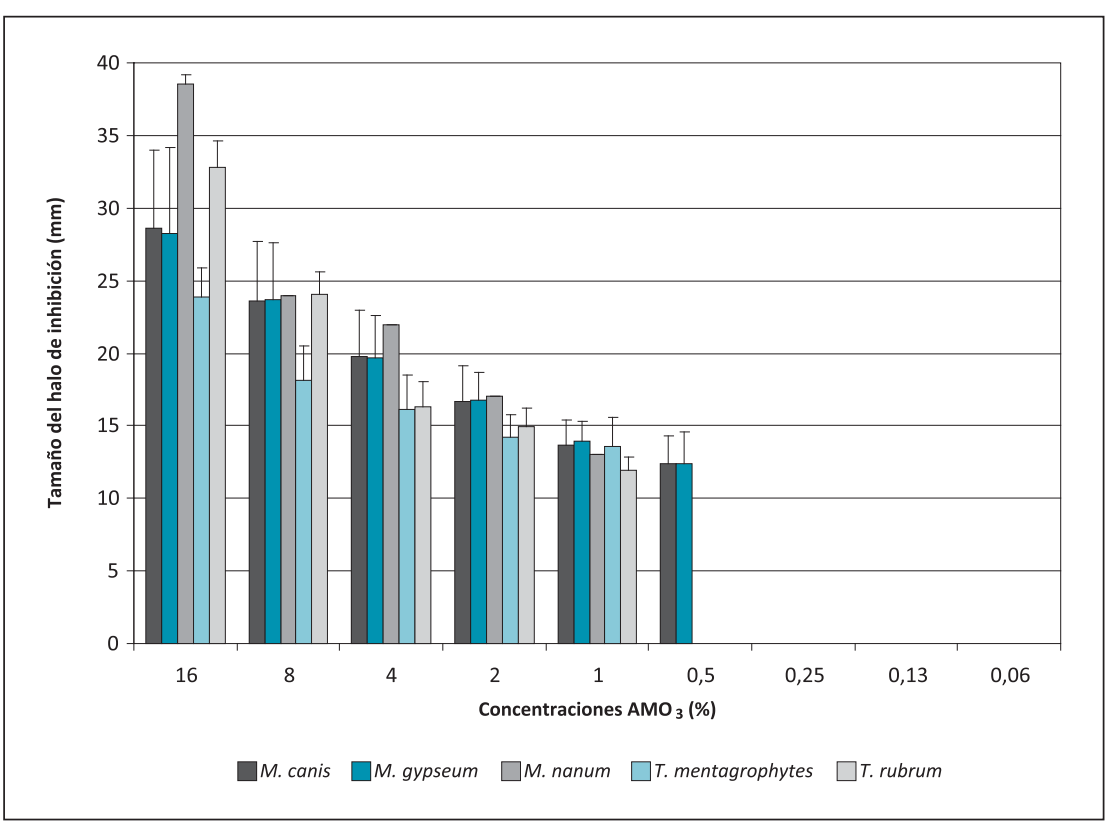

Figura 1. Tamaño del halo de inhibición producido por la actividad del $\mathrm{AMO}_{3}$ en discos con distintas concentraciones frente a 41 cepas de dermatofitos (promedio y desviación estándar).

taron máxima puntuación de gravedad clínica antes del inicio del tratamiento. Los tres grupos tratados con $\mathrm{AMO}_{3}$ manifestaron una evolución positiva, con una disminución significativa de los signos a partir del día 15 de tratamiento en comparación a los grupos controles sin tratamiento y placebo $(\mathrm{p} \leq 0,05)$. Los animales tratados con $\mathrm{AMO}_{3}$, evolucionaron hacia el mejoramiento clínico, alcanzando valores menores o iguales a 1 en la escala arbitraria. En tanto que los grupos controles, al día 30 de tratamiento, su evolución disminuyó menos de 4 puntos, alcanzando

\begin{tabular}{|c|c|c|c|c|c|}
\hline Especie & $\mathbf{n}$ & $\begin{array}{l}\text { Rango CIM } \\
\left(\% \mathrm{AMO}_{3}\right)\end{array}$ & $\begin{array}{c}\mathrm{CIM}_{50} \\
\left(\% \mathrm{AMO}_{3}\right)\end{array}$ & $\begin{array}{c}\mathrm{CIM}_{90} \\
\left(\% \mathrm{AMO}_{3}\right)\end{array}$ & $\begin{array}{c}\text { CFM } \\
\left(\% \mathrm{AMO}_{3}\right)\end{array}$ \\
\hline c. krusei ATCC 6258 & 01 & $0,250-2$ & 1 & 1 & $>16$ \\
\hline C. parapsilosis ATCC 22019 & 01 & $0,250-2$ & 1 & 1 & $>16$ \\
\hline \multicolumn{6}{|l|}{ Dermatofitos } \\
\hline M. canis & 15 & $0,125-1$ & 0,5 & 1 & 1 \\
\hline M. gypseum & 10 & $0,125-1$ & 0,5 & 1 & 1 \\
\hline M. nanum & 01 & 0,250 & 0,250 & 0,250 & 0,5 \\
\hline T. mentagrophytes & 09 & $0,125-0,50$ & 0,5 & 0,50 & 2 \\
\hline Trubrum & 06 & $0,125-0,250$ & 0,250 & 0,250 & 2 \\
\hline Total dermatofitos & 41 & $0,125-1$ & 0,5 & 1 & 2 \\
\hline
\end{tabular}


un registro superior a 8 (Figura 4). Micológicamente, al finalizar el estudio todos los animales de ambos grupos controles presentaron cultivo positivo de dermatofitos. En cambio los grupos tratados con $\mathrm{AMO}_{3}$ al 1\%, 2\% y $3 \%$ exhibieron una cura micológica de 80, 93 y $100 \%$, respectivamente, representando en su conjunto al $94 \%$ de los animales tratados.
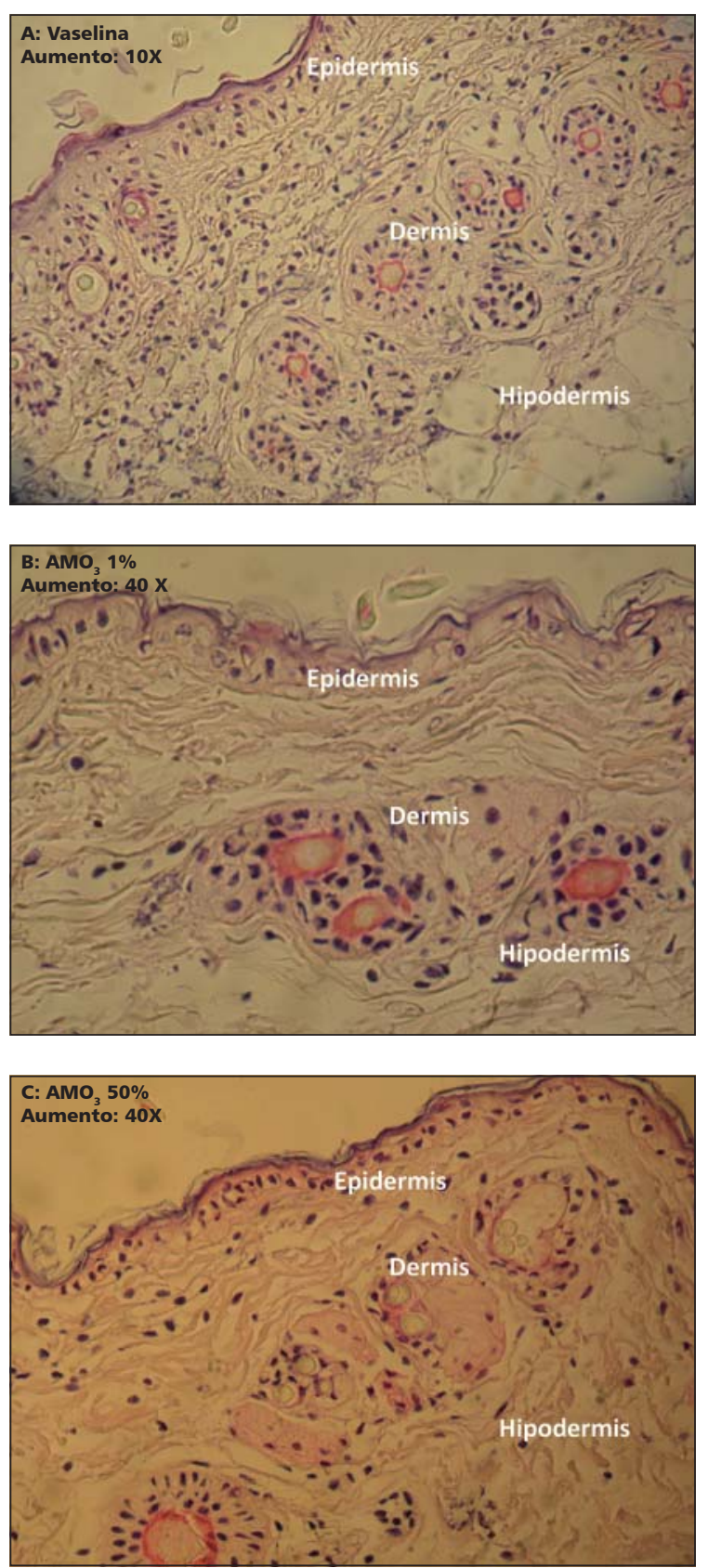

Figura 2. Microfotografía de secciones histológicas de piel de ratón teñida con H\&E y obtenidas a los 30 días de aplicación de vaselina líquida (A), $\mathrm{AMO}_{3} 1 \%$ (B) y $\mathrm{AMO}_{3} 50 \%$ (C), respectivamente.

\section{Discusión}

En el último tiempo, las patologías fúngicas han tenido un aumento creciente en la población humana y animal, lo que sumado a la resistencia de algunos antimicrobianos, ha estimulado el desarrollo de nuevas moléculas de origen sintético y natural, buscando mayor eficacia, espectro de acción y potencia. Entre éstos, existen productos de origen natural que por su composición son mejor tolerados por el hospedero y muchas veces conllevan más de un beneficio para los pacientes ${ }^{9-13}$. Entre los productos naturales con actividad antimicrobiana de uso tópico destacan el aceite derivado del árbol del té28, aceites esenciales y compuestos sulfhídricos de ajos ${ }^{13}$ y de plantas silvestres como canela, sasafrás y bulbos ${ }^{14-18}$, así como el aceite de maravilla ozonizado ${ }^{20-23,34,35}$. Sin embargo, se requiere optimizar los productos naturales con el objetivo de avanzar hacia fármacos más activos, seguros y estables que permitan su proyección hacia el uso individual o combinado con moléculas tradicionales en el tratamiento de pacientes ${ }^{9,11}$.

En la presente investigación se evaluó la actividad antifúngica in vitro, así como la seguridad y rendimiento in

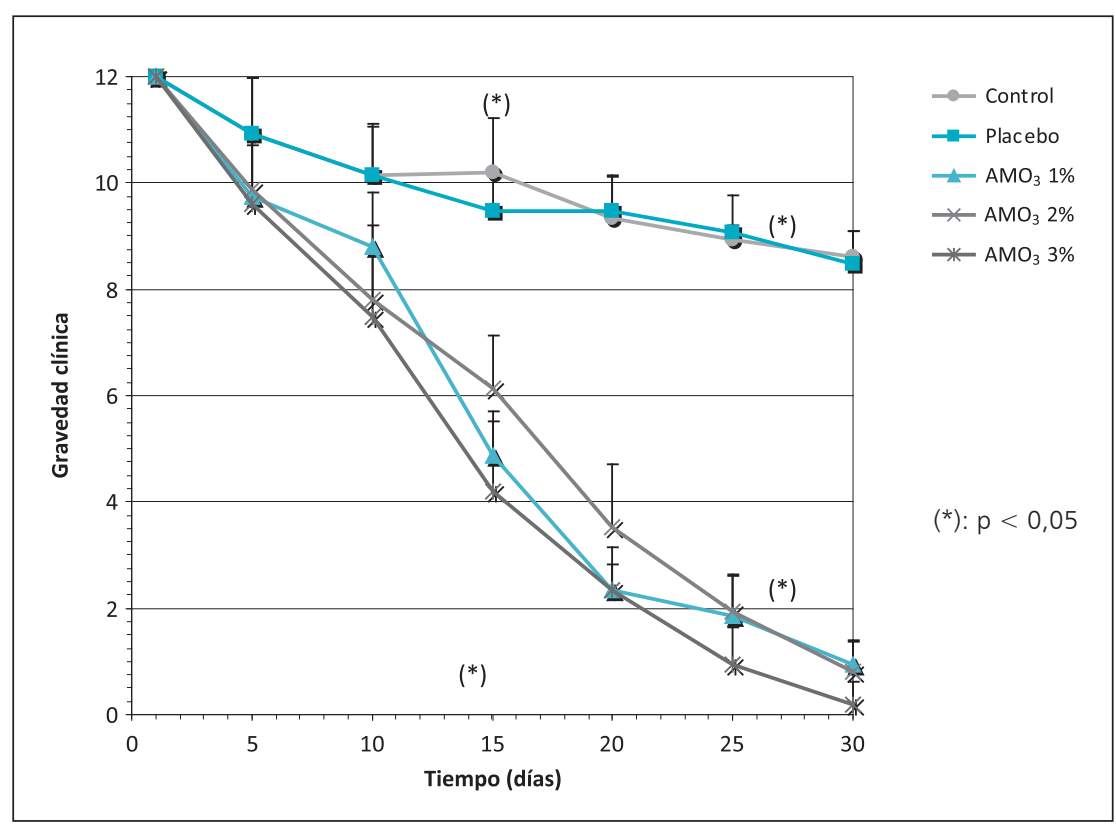

Figura 3. Seguimiento de la evolución clínica durante los 30 días, en los cinco grupos tratados según la valoración de eritema, descamación, prurito y alopecia, siguiendo la escala arbitraria establecida. Evolución clínica de los cinco grupos de animales; Control sin tratamiento (--0--); Placebo (-- $\square--$ ); tratados con $\mathrm{AMO}_{3}$ al $1 \%\left(--\triangle_{--}\right.$; Tratados con $\mathrm{AMO}_{3}$ al $2 \%(--x--)$ y Tratados con $\mathrm{AMO}_{3}$ al $3 \%$ $\left(--_{*}^{--}\right)$. Los valores fueron obtenidos de la escala arbitraria semi-cuantitativa diseñada, donde a cada signo se le atribuyó un puntaje ascendente de cero a tres, donde 0 fue ausencia de lesión, 1: lesión leve, 2: moderada y 3: abundante manifestación clínica, siendo los valores máximo y mínimo de 12 y 0 puntos, respectivamente. Se observan diferencias estadísticamente significativas entre la evolución clínica favorable de los grupos tratados y los controles $(p \leq 0,05)$. 
vivo del aceite de maravilla ozonizado denominado $\mathrm{AMO}_{3}$ en la dermatofitosis, empleando un modelo experimental con ratón adulto cepa CF1. Este producto se generó a través de un proceso original que implica la modificación del aceite, previo a la ozonización, lo que permite obtener un producto con elevada actividad antimicótica y baja viscosidad, facilitando su incorporación y mezcla con excipientes, así como su penetración en el tejido. Existe otro producto a base de aceite de maravilla ozonizado, denominado Oleozon $\AA$; sin embargo, este aceite es ozonizado directamente sin tratamiento previo ${ }^{20,22,35}$.

Por difusión en agar se determinó que $\mathrm{AMO}_{3}$ presentó actividad sobre todas las cepas de dermatofitos evaluadas, contribuyendo a demostrar el amplio espectro de acción de este producto natural ozonizado ${ }^{20-24,26}$. Los resultados obtenidos son alentadores si se comparan con otros productos naturales, donde se evaluó la actividad de varios aceites esenciales frente a dermatofitos, observándose actividad en $80 \%$ de las cepas estudiadas, con halos de inhibición mayores a $10 \mathrm{~mm}^{14}$, siendo estos valores inferiores a los observados en este estudio.

Mediante microdilución en placas, se obtuvo valores de $\mathrm{CIM}$ y $\mathrm{CFM} \leq 1 \% \mathrm{y} \leq 2 \%$ de $\mathrm{AMO}_{3}$ para las cepas de dermatofitos, respectivamente, lo que indica que este nuevo producto presenta un importante efecto fungicida sobre estos hongos en concentraciones levemente superiores a la CIM. Sin embargo, la actividad de $\mathrm{AMO}_{3}$ en las cepas de referencia C. krusei ATCC 6258 y C. parapsilosis ATCC 22019 indica un efecto fungistático debido a que persistió el crecimiento en el pocillo de máxima concentración del producto natural $(16 \%)$. Anteriormente se ha evaluado la actividad de aceites esenciales frente a especies de hongos filamentosos obteniéndose rangos de CIM entre 1 y $4 \%{ }^{36}$, inhibiendo el crecimiento con valores más altos que los obtenidos con el producto natural $\mathrm{AMO}_{3}$ utilizado en esta investigación. La actividad del aceite derivado del árbol del té frente a dermatofitos reporta un valor de CFM $\leq \mathrm{a}$ $8 \%{ }^{28}$, siendo superior a lo obtenido en este estudio.

La evaluación clínica e histopatológica en la presente investigación indica que el producto natural $\mathrm{AMO}_{3}$ es seguro de aplicar vía tópica y no produce alteraciones macro ni microscópicas en la dermis de ratones Mus musculus, siendo similar a lo presentado por Martínez y cols. ${ }^{29}$ quienes evaluaron la toxicidad del aceite de maravilla ozonizado en ratones y conejos, estableciendo que $2.000 \mathrm{mg}$ del aceite por kilo de peso y aplicado sobre el epitelio de ratones no produce efectos tóxicos, ni modifica el peso corporal, sólo ocasiona una leve acción irritante sobre la piel y nulo efecto sobre distintos órganos. Sin embargo, el diseño del estudio difiere del aquí propuesto, ya que los autores realizaron la depilación a ambos flancos del animal, manteniendo luego un parche de gasa con $0,5 \mathrm{ml}$ del aceite ozonizado durante 14 días. En la presente investigación se aplicó $\mathrm{AMO}_{3}$ en dos áreas
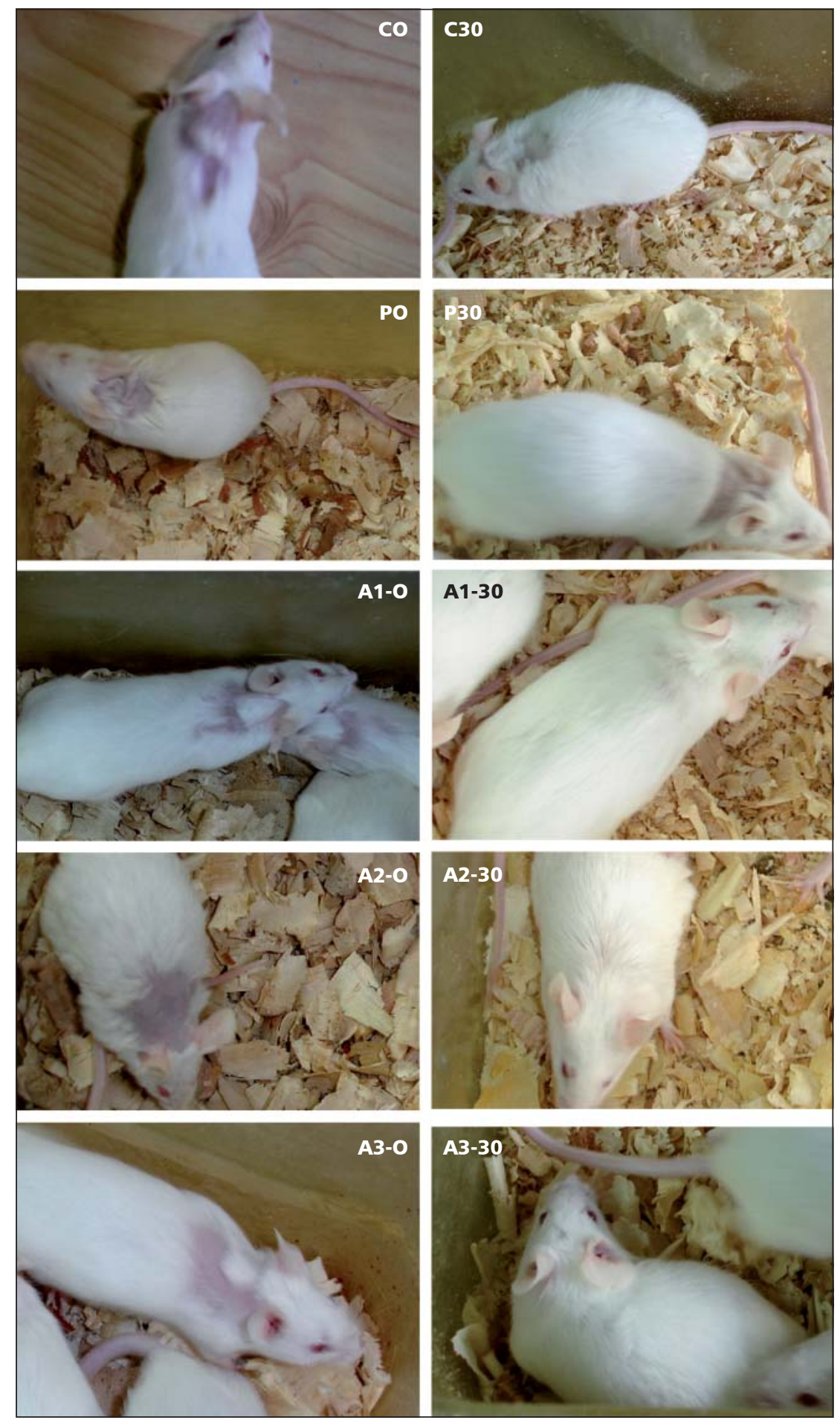

Figura 4. Registro fotográfico de animales representativos de los cinco grupos al día 0 y 30 de tratamiento, mostrando la evolución de las lesiones causadas por dermatofitos en los grupos controles y en los tratados con $\mathrm{AMO}_{3}$ en sus distintos porcentajes. $\mathbf{C 0}$ y $\mathbf{C 3 0}$ (Grupo Control al día 0 y 30). P0 y P30 (Grupo Placebo al día 0 y 30). A1-0 y A1-30 (Grupo $\mathrm{AMO}_{3} 1 \%$ al día 0 y 30). A2-0 y A2-30 (Grupo $\mathrm{AMO}_{3} 2 \%$ al día 0 y 30). A3-0 y A3-30 (Grupo $\mathrm{AMO}_{3} 3 \%$ al día 0 y 30). Se observa la mejora clínica en los grupos tratados al comparar con los animales controles. 
corporales distintas (zona inter-escapular y abdomen) por 30 días. Si bien en el estudio de seguridad los animales no fueron depilados, para evitar micro-lesiones, la zona del abdomen es un área prácticamente desprovista de pelos, lo que hace confiable el modelo animal empleado en este trabajo, considerando que un grupo fue expuesto al producto concentrado como sobredosis.

La actividad antifúngica de $\mathrm{AMO}_{3}$ en crema fue evaluada favorablemente en el modelo de dermatofitosis experimental empleado, destacando que a partir del día 15 se apreció clínicamente una diferencia significativa con los grupos controles, terminando a los 30 días con cura clínica en todos los individuos de los tres grupos de animales tratados con este nuevo producto natural y con una cura micológica de 93 y 100\% en los grupos tratados con $\mathrm{AMO}_{3}$ al 2 y $3 \%$, respectivamente. Este resultado es superior a lo mostrado por Menéndez y cols. (2002), quienes aplicaron aceite de maravilla ozonizado en pacientes con tinea pedis dos veces por día, durante seis semanas alcanzando cura clínica y micológica de $75 \%{ }^{34}$, lo cual podría ser explicado en parte por el proceso modificado de tratamiento del aceite de maravilla previa ozonización, implementado en este estudio. Recientemente, se refuerza el gran espectro de aplicación de estos productos naturales al evidenciar que el aceite de maravilla ozonizado puede ser también una alternativa para el tratamiento tópico en onicomicosis, aplicado dos veces por día durante tres meses con rendimiento de $90,5 \%{ }^{35}$.

Los resultados de la presente investigación indican que $\mathrm{AMO}_{3}$ en crema es una alternativa segura para el tratamiento tópico de las dermatofitosis, sin generar reacciones adversas, demostrado a través de modelos animales estandarizados, que aportan en el proceso de validación.

En conclusión, $\mathrm{AMO}_{3}$ presenta actividad antifúngica frente a distintas especies de dermatofitos, es seguro de aplicar vía tópica y tiene una elevada actividad en modelo de dermatofitosis experimental animal. Recomendamos estudios futuros de asociación con fármacos químicos disponibles para evaluar el potencial sinergismo con el propósito de disminuir las dosis, días de tratamiento y aumentar el rendimiento terapéutico en pacientes que presenten la infección natural.

Agradecimientos. A la empresa biotecnológica "Bioinnovación" por proporcionarnos el aceite de maravilla ozonizado $\left(\mathrm{AMO}_{3}\right)$ y las cremas dermatológicas.

\section{Resumen}

Se evaluó la seguridad y actividad antifúngica del aceite de maravilla ozonizado $\left(\mathrm{AMO}_{3}\right)$ frente a dermatofitos. $\mathrm{AMO}_{3}$ se generó a través de un proceso original que implica modificación del aceite previa ozonización por esterificación catalítica con alcohol. La sensibilidad fue estudiada en 41 dermatofitos por difusión en agar y microdilución en caldo. El modelo experimental para evaluar tópicamente la seguridad del aceite incluyó 60 ratones $\mathrm{CF} 1$, formando tres grupos a los cuales se les aplicó respectivamente vaselina (control), $\mathrm{AMO}_{3} 1 \%$ y $\mathrm{AMO}_{3} 50 \%$ (sobredosis). Luego, se indujo dermatofitosis experimental en ratones CF1, seleccionando 75 individuos divididos en cinco grupos tratados una vez al día con placebo, crema con $\mathrm{AMO}_{3}$ al 1\%, 2\% y $3 \%$, más un grupo control sin tratamiento. Este nuevo producto natural presentó actividad antifúngica frente a todas las cepas estudiadas. La CIM fluctuó entre 0,125 y $1 \%$ mientras la concentración fungicida mínima (CFM) fue de 2\%. La aplicación de $\mathrm{AMO}_{3}$ no generó lesiones clínicas ni histopatológicas. Los ratones con dermatofitosis tratados con $\mathrm{AMO}_{3}$ presentaron $100 \%$ de cura clínica y $94 \%$ de promedio en cura micológica, siendo superior al grupo control y placebo $(\mathrm{P}<0,05)$. Este producto muestra elevada actividad antimicótica y podría ser una alternativa segura para tratamiento tópico de dermatofitosis.

\section{Referencias}

1.- González J F, Bárcena M C. Ecología de las dermatofitosis. Rev Iberoam Micol 1996; 13: 47-54.

2.- Know-Chung K J, Bennett J W. Dermatophytes. Know-Chung K J, Bennett J W, editors. Medical Mycology. Leal Febiger, Philadelphia PA; 1992, p. 43-65.

3.- Escuita B, Febrer I, Permán J, Oliver V, Sánchez-Carazo J L. Tinea capitis por Microsporum audouini. Rev Iberoam Micol 2001; 18: 88-90.

4.- Sidrim J J, Rocha M F. Aspectos clínicoslaboratoriais das dermatofitotisis. Sidrim J J, Rocha M F, editors. Micologia Médica a Luz de
Autores Contemporaneos. Guanabara Koogan, Río de Janeiro; 2004, p. 135-55.

5.- Barnetson R S, Marley J. Bullñen M, Brookman S, Cowen P, Ellis D, Williams T. Comparison of one week of oral terbinafine $(250 \mathrm{mg}$ /day) with four week of treatment with clotrimazole $1 \%$ cream in interdigital Tinea pedis. Br J Dermatol 1998; 139: 675-8.

6.- Del Palacio A, Garau M, Cuétara M S. Tratamiento actual de las dermatofitosis. Rev Iberoam Micol 2002; 19: 68-71.

7.- Maestre J R, Alou L. Ventajas y desventajas de los antifúngicos de uso tópico. Rev Esp Quimioter 2001; 14: 17-21.

8.- Mesa A C, Bueno J G, Betancur L A. Productos naturales con actividad antimicótica. Rev Esp Quimioterap 2004; 17: 325-31.

9.- Tasleem A, Bhosale J D, Kumar N, Mandal T K, Bendre R S, Lavekar G S, et al. Natural products-antifungal agents derived from plant. J As Nat Prod Res 2009; 7: 621-38.

10.- Di Santo R. Natural products as antifungal agents against clinically relevant pathogens. Nat Prod Rep 2010; 27: 1084-98.

11.- Roemer T, Xu D, Singh SB, Parish C A, Harris G, Wang H, et al. Confronting the challenges of natural product-based antifungal discovery. Chem Biol 2011; 18: 148-64.

12.- World Health Organization. Aetheroleum Melaleucae Alternifoliae. WHO monographs on selected medicinals plants. WHO Graphics 
Geneva; 2002, p. 172-9.

13.- Ledezma E, Marcano K, Jorquera A. Efficacy of ajoene in the treatment of tinea pedis: A doubleblind and comparative study with terbinafine. J Am Acad Dermatol 2000; 43: 829-32.

14.- Lima E O, Fishman O, Giesbrecht A M, Paula M Q. In vitro antifungal activity of essential oils obtained from oficinal plants against dermatophytes. Mycoses 1993; 36: 333-6.

15.- Lima E O, Farías N M. Atividade antifúngica de óleos esenciáis, obtidos de plantas medicinais contra levaduras do género Candida. Rev Braz Cs Sal 1999; 3: 51-64.

16.- Tequida M, Cortez M, Rosas E, López S, Corrales C. Efecto de extractos alcohólicos de plantas silvestres sobre la inhibición del crecimiento de Aspergillus flavus, Aspergillus níger, Penicillium chrysogenum, Penicillium expansum, Fusarium moniliforme y Fusarium poae. Rev Iberoam Micol 2002; 19: 84-8.

17.- Gayoso C W, Lima E O, Oliveira V T, Pereira F O, Souza EL, Lima I O, et al. Sensitivity of fungi isolated from onychomycosis to Eugenia cariophyla essential oil and Eugenol. Fitoterapia 2005; 76: 247-9.

18.- Lima E O, Belém L F, Filho V C, Correa R, Nunes R J, Andricopulo A, et al. Avaliação da sensibilidade de cepas de Malassezia furfur a imidas cíclicas. Braz J Phar Sc 2002; 38: 443-9.

19.- Gil S. Tesis Doctoral. Determinación del ozono atmosférico de las medidas de MIPAS/ ENVISAT. Departamento de Física Aplicada. Universidad de Granada, España, 2006. http: // hera.ugr.es/tesisugr/15934214.pdf,

20.- Sechi L A, Lezcano I, Núñez N, Espim M, Dupre I, Pinna A, et al. Antibacterial activity of ozonized sunflower oil (Oleozon). J Appl Microbiol 2001; 90: 279-84.

21.- Lezcano I, Núñez N, Molerio J, Gómez M. Actividad in vitro del aceite de girasol ozonizado frente a diferentes especies microbianas. Rev CENIC Cs Biol 1996; 27 : 46-50.

22.- Lezcano I, Molerio J, Gómez M, Contreras R, Díaz W. Actividad in vitro del OLEOZON frente a agentes etiológicos de infecciones de la piel. Rev CENIC Cs Biol 1998; 29: 209-12.

23.- Contreras O R, Gómez M, Menéndez S, Molerio J, Roura G, Fernández D. Efecto de la sustitución del aceite de oliva por aceite de girasol en la actividad antimicrobiana del aceite ozonizado. Rev CENIC Cs Quim 1989; 20: 121-4.

24.- Díaz M, Hernández R, Martínez G, Vidal G, Gómez M, Fernández H, et al. Comparative study of ozonized sunflower oil. J Braz Chem Soc 2006; 17: 403-7.

25.- De Hoog G, Guarro J, Gené J, Figueras M. Athlas of clinical fungi. Central Bureau for Schimmecultures, Netherlands-Universitat Rovira et Virgili, Spain; 2000, p. 342-6.

26.- Silva V, Hernández J, Herrera L. Sensibilidad antifúngica de dermatofitos, Malassezia spp y Candida spp, frente a un producto natural a base de aceite de maravilla ozonizado $\left(\mathrm{AMO}_{3}\right)$. Anales de la XXV Reunión Anual de Dermatología Latinoamericana (RADLA), Santiago-Chile, 13 al 16 de Mayo, 2006.

27.- National Committee for Clinical Laboratory Standards. Reference method for broth dilution antifungal susceptibility testing of conidiumforming filamentous fungi, proposed standard M38-A. National Committee for Clinical Laboratory Standards, Wayne, USA, 2002
28.- Hammer K A, Carson C F, Riley TV. In vitro activity of Melaleuca alternifolia (tea tree) oil against dermatophytes and other filamentous fungi. J Antimicrob Chemother 2002; 50: 195-9.

29.- Martínez S, Fernández L, Torres-Rodríguez C. Toxicidad aguda dérmica del aceite ozonizado "Oleozon" en ratas y conejos: rol de los radicales libres. Rev CENIC Cs Biol 1999; 28 : 35-9.

30.- Robert N. Mechanisms of glucocorticoids of action; what is important? Thorax 2000; 55: 603-13.

31.- Ghannoum M A, Hossain M A, Long L, Mohamed S, Reyes G, Mukherjee P K. Evaluation of antifungal efficacy in an optimized animal model of Trichophyton mentagrophytes-dermatophytosis. J Chemother 2004; 16: 139-44.

32.- Niwano Y, Tabuchi T, Kanai K, Hamaguchi H, Uchida K, Yamaguchi H. Short-term topical therapy of experimental Tinea pedis in guinea pigs with lanoconazole, a new imidazole antimycotic. Antimicrob Agent Chemother 1995; 39: 2353-5.

33.- Svecoda D. Experimental Trichophyton rubrum infection in animals. Epidemiol Microbiol Immunol 2000; 49: 75-9.

34.- Menéndez S, Falcón L, Simón D, Landa N. Efficacy ozonized sunflower oil in the treatment of tinea pedis. Mycoses 2002; 45: 329-32.

35.- Menéndez S, Falcón L, Maqueira Y. Therapeutic efficacy of topical Oleozon ${ }^{\circledR}$ in patients suffering from onychomycosis 2010; May 17. doi: 10.1111/j.1439-0507.2010.01898.x.

36.- Leite E, Lima E, Freire K, Sousa C. Inhibitory action of some essential oils and phytochemicals on the growth of various moulds isolated from foods. Braz Arch Biol Tech 2005; 48: 245-50. 